\title{
Diverticular Disease risk reduced with a Plant-Based Diet
}

\author{
Stewart D Rose and Amanda J Strombom* \\ Plant-Based Diets in Medicine, USA
}

Submission: November 22, 2019; Published: December 05, 2019

*Corresponding author: Amanda Strombom, Plant-Based Diets in Medicine, 12819 SE 38th St, \#427, Bellevue, WA 98006, USA

Abstract

By age 60, two-thirds of all Americans will develop diverticulosis, and a significant percentage will go on to develop acute diverticulitis. Epidemiological studies show that the risk of diverticulitis is reduced significantly, the less red meat, refined grains and high fat dairy are consumed, and the more fruits, vegetables and whole grains are included in the diet.

The prevalence of diverticular disease in vegetarians was found to be $27 \%$ less and for vegans was $72 \%$ less than for meat eaters. Dietary fiber is an independent risk factor, reducing the risk by $41 \%$ for those consuming the most fiber, so one reason vegetarians, and especially vegans, have lower rates of diverticular disease may be their higher fiber intake. They also have a lower incidence of other risk factors such as obesity and hypertension. The properties of plant foods (the phytonutrients they contain) and the healthier and less inflammatory intestinal flora that vegetarians and especially vegans have, also contribute significantly to their reduced incidence of diverticulosis and diverticulitis and its complications.

The clinical implications of the research so far indicate a plant-based, or vegan diet, emphasizing high fiber, especially insoluble fiber, should be prescribed for all patients at risk of diverticular disease.

Keywords: Diverticulitis; Diverticulosis; Fiber; Vegan; Vegetarian; Western diet

\section{Introduction}

By age 60, two-thirds of all Americans will have developed diverticulosis [1]. A significant percentage of patients with diverticulosis will go on to develop acute diverticulitis. This imposes a significant burden on healthcare systems, resulting in greater than 300,000 admissions per year with an estimated annual cost of $\$ 3$ billion [2]. There is considerable evidence that a high fiber, plant-based diet is effective at reducing the risk of this painful condition.

The western diet, high in red meat, refined grains, and highfat dairy, and a prudent diet, high in fruits, vegetables, and whole grains, were compared for risk of diverticulitis. The highest quintile of Western dietary pattern score had a 55\% greater risk of diverticulitis compared to the lowest quintile. Even within the prudent diet group, high prudent diet scores were associated with decreased risk of diverticulitis of $26 \%$ [3].

Another study compared with men in the lowest quintile of total red meat consumption to men in the highest quintile. The latter had an increased risk of diverticulitis of 58\% [4]. A case control study and two large-scale prospective cohort studies found that frequent consumption of red meat is a risk factor for diverticular disease or for hospitalization as a result of diverticular disease [5-7].

In 1979, a research article in the British journal, the Lancet, reported that the prevalence of diverticular disease in vegetarians was almost one third that of meat eaters. It was noted in this study that vegetarians had a mean intake of fiber of $42 \mathrm{gm} /$ day compared to $21 \mathrm{gm} /$ day for meat eaters [8]. In a more recent study, vegetarians were found to be at a $30 \%$ decreased risk of diverticulosis compared with omnivores [9].

In a more detailed British study, the relative risk of diverticular disease was found to be $27 \%$ less for vegetarians and $72 \%$ less for vegans compared to meat eaters [10]. Dietary fiber was also determined to be an independent factor, reducing the relative risk of diverticular disease by $41 \%$ for those consuming the most. Other important variables were obesity, hypertension, cigarette smoking, hormone replacement therapy and oral contraceptives. 
One of the reasons vegetarians, and especially vegans, have lower rates of diverticular disease may be their higher fiber intake, and a lower incidence of other risk factors such as obesity and hypertension [11]. It may also be reasonably hypothesized that the properties of plant foods (the phytonutrients they contain) and the healthier and less inflammatory intestinal flora that vegetarians and especially vegans have, contribute significantly to their reduced incidence of diverticulosis and diverticulitis and its complications [12].

While one study showed a smaller association between fiber and diverticulosis [13], its results should be regarded with caution partly because of its methodology and partly because of the greater weight of evidence showing an association between dietary fiber is very well established $[5,6,14]$.

A lack of dietary fiber is firmly anchored in the literature as the most important lifestyle associated risk factor for the development of diverticulosis as well as diverticular disease $[15,16]$. There is agreement that there are considerable benefits of fiber for the management of other diseases and overall health; we therefore should continue to recommend fiber as part of a healthy diet $[17,18]$.

The notion that individuals with diverticular disease should avoid nuts, seeds, corn, and popcorn are based on the hypothesis that their fragments could impact and obstruct a diverticulum, thereby causing diverticulitis or a diverticular hemorrhage. However, a large prospective documented an inverse relationship between nut and popcorn consumption and the risk of diverticulitis. Furthermore, no associations were observed between corn consumption and diverticulitis or between nut, corn, or popcorn consumption and diverticular hemorrhage or uncomplicated diverticulosis [19].

\section{Discussion}

The etiology for diverticular disease may be more complicated than once thought. However, the clinical implications of the research so far indicate that a plant-based, or vegan, diet that emphasizes high fiber, especially insoluble fiber, would be indicated, and should be prescribed for all patients at risk of diverticular disease [20].

\section{References}

1. Floch M, Bina I (2004) The natural history of diverticulitis: fact and theory. J Clin Gastroenterol 38(5 Suppl 1): S2-S7.

2. Agarwal A, Karanjawala B, Maykel J, Johnson E, Steele S (2014) Routine colonic endoscopic evaluation following resolution of acute diverticulitis: Is it necessary? World J Gastroenterol 20(35): 1250912516.
3. Strate L, Keeley B, Cao Y, Wu K, Giovannucci E, Chan AT, et al. (2017) Western Dietary Pattern Increases, Whereas Prudent Dietary Pattern Decreases, Risk of Incident Diverticulitis in a Prospective Cohort Study. Gastroenterology 152(5): 1023-1030.

4. Cao Y, Strate L, Keeley B, Tam I, Wu K, et al. (2018) Meat intake and risk of diverticulitis among men. Gut 67(3): 466-472.

5. Aldoori W, Giovannucci E, Rimm E, Wing A, Trichopoulos D, et al. (1994) A prospective study of diet and the risk of symptomatic diverticular disease in men. Am J Clin Nutr 60(5): 757-764.

6. Aldoori W, Giovannucci E, Rockett H, Sampson L, Rimm E, et al. (1998) A Prospective Study of Dietary Fiber Types and Symptomatic Diverticular Disease in Men. J Nutr 128(4): 714-719.

7. Manousos O, Day N, Tzonou A, Papadimitriou C, Kapetanakis A, et al. (1985) Diet and other factors in the aetiology of diverticulosis: an epidemiological study in Greece. Gut 26(6): 544-549.

8. Gear J, Ware A, Fursdon P, Mann J, Nolan D, et al. (1979) Symptomless diverticular disease and intake of dietary fibre. Lancet 1(8115): 511514 .

9. Peery A, Sandler R,Ahnen D, Galanko J, Holm A, etal. (2013) Constipation and a Low-Fiber Diet Are Not Associated With Diverticulosis. Clin Gastroenterol Hepatol 11(12): 1622-1627.

10. Crowe F, Appleby P, Allen N, Key T (2011) Diet and risk of diverticular disease in Oxford cohort of European Prospective Investigation into Cancer and Nutrition (EPIC): prospective study of British vegetarians and non-vegetarians. BMJ 343: d4131.

11. Yeo L, Tseng T, Chen W, Kao T, Wu L, et al. (2019) Hypertension control and risk of colonic diverticulosis. Therap Adv Gastroenterol 12:1756284819855734.

12. Kim M, Hwang S, Park E, Bae J (2013) Strict vegetarian diet improves the risk factors associated with metabolic diseases by modulating gut microbiota and reducing intestinal inflammation. Environ Microbiol Rep 5(5): 765-775.

13. Barroso A, Quigley E (2015) Diverticula and Diverticulitis: Time for a Reappraisal. Gastroenterol Hepatol (N Y) 11(10): 680-688.

14. Böhm S (2015) Risk Factors for Diverticulosis, Diverticulitis, Diverticular Perforation, and Bleeding: A Plea for More Subtle History Taking. Viszeralmedizin 31(2): 84-94.

15. Böhm S (2010) Divertikelkrankheit. Bremen: Uni-Med.

16. Strate L (2012) Lifestyle factors and the course of diverticular disease. Dig Dis 30(1): 35-45.

17. Burgell R, Muir J, Gibson P (2013) Pathogenesis of Colonic Diverticulosis: Repainting the Picture. Clin Gastroenterol Hepatol 11(12): 1628-1630.

18. Floch M (2014) Is there really anything new on dietary fiber in colonic diverticular disease? Clin Gastroenterol Hepatol 12(7): 1200-1201.

19. Strate L, Liu Y, Syngal S, Aldoori W, Giovannucci E (2008) Nut, Corn, and Popcorn Consumption and the Incidence of Diverticular Disease. JAMA 300(8): 907-914.

20. Aldoori W, Ryan-Harshman M (2002) Preventing diverticular disease. Review of recent evidence on high-fibre diets. Can Fam Physician 48: 1632-1637. 
This work is licensed under Creative Commons Attribution 4.0 License DOI: 10.19080/ARGH.2019.14.555884

\section{Your next submission with JuniperPublishers} will reach you the below assets

- Quality Editorial service

- Swift Peer Review

- Reprints availability

- E-prints Service

- Manuscript Podcast for convenient understanding

- Global attainment for your research

- Manuscript accessibility in different formats ( Pdf, E-pub, Full Text, audio)

- Unceasing customer service

Track the below URL for one-step submission https://juniperpublishers.com/online-submission.php 